Pak. j. sci. ind. res. Ser. A: phys. sci. 2014 57(2) 59-62

\title{
Percentage Discrepancies Assessment Between Measured and Calculated Behaviour of Percent Depth Dose in External Beam Radiotherapy
}

\author{
Muhammad Isa $^{\text {ab*, Khalid Iqbal }}{ }^{\text {ab }}$, Muhammad Jahanzeb Ashraf ${ }^{\text {a }}$, Muhammad Afzal ${ }^{a}$ \\ and Saeed Ahmad Buzdar ${ }^{\mathrm{a}}$ \\ ${ }^{a}$ Department of Physics, The Islamia University, Bahawalpur, Pakistan \\ ${ }^{b}$ Department of Radiation Oncology, Shaukat Khanum Cancer Hospital and \\ Research Center, Lahore, Pakistan
}

(received October 24, 2012; revised February 25, 2013; accepted April 19, 2013)

\begin{abstract}
The aim of this study was to calculate percentage discrepancies (PD) of the measured and calculated percentage depth doses (PDDs) values. The $6 \mathrm{MV}$ photon beam produced by the Varian linear accelerator $2100 \mathrm{C} / \mathrm{D}$ was used in this study. PDDs, tissue maximum ratios (TMR) and phantom scatter factor $\left(\mathrm{S}_{\mathrm{p}}\right)$ were measured using the PTW 31006 ionisation chamber in water phantom. PD between PDD values of the measured and calculated was ranging between $0.30 \%$ and $2.38 \%$. Percentage discrepancies were also found higher against $20 \mathrm{~cm}$ depth in water for $(20 \times 20) \mathrm{cm}^{2}$ field size. These discrepancies should be taken into account, while delivering any medical dose in radiation therapy centers.
\end{abstract}

Keywords: percentage depth dose, percentage discrepancies, ionisation chamber

\section{Introduction}

Medical linear accelerators are playing important role in radiation centres all over the world. Specific radiation dose is applied to cancer patients for curative as well as palliative treatment. However, for each case the prescribed dose ought to be delivered accurately both in quantity and quality. Over or under-dosage could be harshly destructive to the patient or may lead to unwanted outcomes. For accuracy concerns supercomputers have been introduced in radiation therapy centres. These computers exploit commercial programmes and algorithms for the management of model dose distributions within the irradiated part of the patient. In order to attain precised output from these modern facilities, they have to be fed with exact beam data measured from the modern treatment machines. Hence, medical physicists are more concerned about quality assurance of accelerators and consistency of the radiation measurements. These measurements are based on daily, monthly and yearly procedures to assure accurate delivery of dose to patient. International Associations and Agencies of Physicists in Medicine (such as AAPM and IAEA) produce updated publications of acceptable tolerance for mechanical actions and radiation field output. These publications are found to promise accomplishment of immense accuracy of dose delivery to the right body volume (IAEA, 2000; Peter et al., 1999).

*Author for correspondence; E-mail: isaiub@yahoo.com
Though, measurements of percentage depth dose (PDD) could be exaggerated by factors, which are not commonly taken into account. These contains movement of water during PDD or beam profile measurements, predominantly when measuring surface dose and physical dimensions of the measuring apparatus such as the ionisation chamber or TLD. Direct formulas can also be sometime used to determine vital radiation quantities. These formulas can be used when the other variable quantities are known. Monte Carlo simulations could be practical in calculating the amount of certain quantities such as PDD, beam profiles; flux and dose delivery to definite position in the treatment room or within the patient (Rogers, 2002; Ahnesjo and Aspradakis, 1999; Bloch and Altschuler, 1995).

Percentage discrepancies may exist due to some properties of measuring devices or attributed to some issues such as movement of water during measurements. It is not understandable why such discrepancies subsist. Exactness in manufacturing may also affects on accuracy (Sameer, 2007). Percentage discrepancies (PD) have been calculated between measured and calculated PDDs at different field sizes and depths. The calculated PDDs were worked out by using formula, with constant SSD. Phantom scatter factor and tissue maximum ratios (TMR) were measured and used in the formula to evaluate the calculated PDDs values. The PD and PD gradient values were computed between the calculated 
and measured PDDs for $6 \mathrm{MV}$ energy. This work provides an alternative approach to radiation oncology physicists about the necessity of quality assurance and this ultimately improves the quality of the treatments.

\section{Materials and Methods}

Since the water behaviour is quite similar with human body, therefore, beam profile and PDDs are usually measured in water phantoms to resemble a patient after introducing correction factors for temperature and pressure. This study was carried out on a PTW scanning water phantom $(40 \times 40) \mathrm{cm}^{2}$ with ionisation chamber of active volume of $0.5 \mathrm{~cm}^{3}$. The ionisation chamber was installed on the moveable sampling holder of the phantom. Another chamber was fixed on the phantom as a reference chamber. The Varian medical accelerator $2100 \mathrm{C} / \mathrm{D}$ having energy of $6 \mathrm{MV}$ was used. The field chamber was moved when the radiation was "ON" and reference chamber was fixed. The output was read out on the electrometer and then the ratio of both chambers' reading was used to make the PDD or dose profile data. The peak absorbed dose on the central axis occurs at the end of build up region. By definition (Birgani and Karbalaee, 2009) the PDD is:

$$
\mathrm{PDD}=\frac{\mathrm{D}_{\mathrm{d}}}{\mathrm{D}_{\max }}
$$

where:

$\mathrm{D}_{\mathrm{d}}=$ dose at depth; $\mathrm{D}_{\max }=$ depth of maximum dose.

Dosimetry studies show that the PDD initially increases rapidly until the depth of the maximum dose is achieved. Beyond this the dose decreases slowly with depth. This study was confirmed by calculating the PDD using the formula of Khan (2010).

$$
P(d, r, f)=\operatorname{TMR}\left(d, r_{d}\right)\left(\frac{f+t_{o}}{f+d}\right)^{2}\left(\frac{S_{p}\left(r_{d}\right)}{S_{p}\left(r_{t o}\right)}\right) \cdot 100
$$

where:

$\operatorname{TMR}\left(\mathrm{d}, \mathrm{r}_{\mathrm{d}}\right)=$ measured tissue maximum ratio;

$\mathrm{f}=\mathrm{SSD} ; \mathrm{r}_{\mathrm{d}}=\mathrm{r} .\left(\frac{\mathrm{f}+\mathrm{d}}{\mathrm{f}}\right) ; \mathrm{r}_{\mathrm{to}}=\mathrm{r} .\left(\frac{\mathrm{f}+\mathrm{t}_{\mathrm{o}}}{\mathrm{f}}\right) ; \mathrm{d}=\operatorname{depth} ;$ $r_{d}=$ field size at reference depth; $t_{o}=$ reference depth at maximum dose; $\mathrm{S}_{\mathrm{p}}\left(\mathrm{r}_{\mathrm{d}}\right)=$ phantom scatter factor at reference depth $\mathrm{d} ; \mathrm{S}_{\mathrm{p}}\left(\mathrm{r}_{\mathrm{t} 0}\right)=$ phantom scatter factor at reference depth at maximum dose.

TMR is used for high energy photon beams. PDDs, TMR and $S_{p}$ values were measured by fixing the reference depth at $1.5 \mathrm{~cm}$ of ionisation chamber in water phantom. $\mathrm{S}_{\mathrm{p}}$ was found by small diameter chamber using measured
PDD data. Then these measured values of TMR, $S_{p}$ and PDDs were used in formula containing equation (2) to calculate PDDs.

\section{Results and Discussion}

Table 1 reveals the $\mathrm{S}_{\mathrm{p}}$, TMR, PDDs values, which were measured using the arrangement as show in Fig. 1. These TMR, $\mathrm{S}_{\mathrm{p}}$, PDDs values were used in formula (2) and new PDDs were calculated. Table 2 shows the measured values and Table 3 shows the calculated values at some selected depths in water. PD was found between the measured and calculated PDDs.

Percentage discrepancies (PD) between PDD values for measured and calculated values are shown in Table 2 at same depth and field size. Taking PDD measured values as a reference; PD values were calculated using the following formula (Sameer, 2007).

$$
\mathrm{PD}=\frac{\mathrm{PDD}_{\text {Calculated }}-\mathrm{PDD}_{\text {Measured }}}{\mathrm{PDD}_{\text {Measured }}} \times 100 \%
$$

The uppermost PD value was found in Fig. 2 and by Table 2 at $(15 \times 15) \mathrm{cm}^{2}$ field size, while the minute value was observed at $1.5 \mathrm{~cm}$ depth for both the $(20 \times 20) \mathrm{cm}^{2}$ and $(25 \times 25) \mathrm{cm}^{2}$ field sizes. Table 3 illustrates the maximum $\mathrm{PD}$ value in this study at $6 \mathrm{MV}$ was $2.38 \%$ at depth $20 \mathrm{~cm}$ with $(15 \times 15) \mathrm{cm}^{2}$ field size, while minimum value $(0.30 \%)$ with the same field size was found at $1.5 \mathrm{~cm}$ near the water surface.

Figure 2 demonstrates the relationship between PD values in Table 2 and field size at each selected depth in water at $6 \mathrm{MV}$.

Figure 2 confirms the values of Table 2 i.e., the PD values improve with depth in water and depreciate with field size. PD gradient shows an increment or decrement in values at each step during delivery of doses. A medical physicist must know the change in dose at every step, while delivering the accurate doses to patients. The maximum PD gradient between these values can be found as:

$$
=\frac{2.38-0.3}{15}=0.1386 \mathrm{~cm}^{-1}
$$

This shows a $0.1386 \%$ increment in PD occurring from every $1 \mathrm{~cm}$ from $D_{\max }$ to depth of $20 \mathrm{~cm}$ that correspond to maximum PD gradient. Similarly, the minimum PD gradient was found at field size of $20 \times 20 \mathrm{~cm}^{2}$ as calculated by:

$$
=\frac{0.22-0.1}{20}=0.006 \mathrm{~cm}^{-1}
$$


Table 1. Measured values of TMR, Phantom scatter factor and others at certain depths and field sizes for $6 \mathrm{MV}$ photon beam

\begin{tabular}{|c|c|c|c|c|c|c|c|c|}
\hline $\begin{array}{l}\text { Field size } \\
\text { (r) }\end{array}$ & $\begin{array}{l}\text { Depth } \\
\text { (d) }\end{array}$ & TMR & $r_{d}$ & $\mathrm{~S}_{\mathrm{p}}\left(\mathrm{r}_{\mathrm{d}}\right)$ & $r_{\text {to }}$ & $\mathrm{S}_{\mathrm{p}}\left(\mathrm{r}_{\mathrm{to}}\right)$ & $\begin{array}{l}\text { Calculated } \\
\text { PDD }\end{array}$ & $\begin{array}{l}\text { Measured } \\
\text { PDD }\end{array}$ \\
\hline \multirow[t]{5}{*}{$5 \times 5$} & 1.5 & 0.992 & 5.075 & 0.968 & 5.075 & 0.968 & 99.2 & 99.6 \\
\hline & 5 & 0.913 & 5.25 & 0.968 & 5.075 & 0.968 & 85.3 & 85.7 \\
\hline & 10 & 0.754 & 5.5 & 0.968 & 5.075 & 0.968 & 64.1 & 64.6 \\
\hline & 15 & 0.611 & 5.75 & 0.968 & 5.075 & 0.968 & 47.5 & 48 \\
\hline & 20 & 0.499 & 6 & 0.974 & 5.075 & 0.968 & 35.4 & 36 \\
\hline \multirow[t]{5}{*}{$10 \times 10$} & 1.5 & 0.993 & 10.15 & 1 & 10.15 & 1 & 99.3 & 99.7 \\
\hline & 5 & 0.929 & 10.5 & 1 & 10.15 & 1 & 86.8 & 87.3 \\
\hline & 10 & 0.797 & 11 & 1.005 & 10.15 & 1 & 67.5 & 68 \\
\hline & 15 & 0.658 & 11.5 & 1.005 & 10.15 & 1 & 51.0 & 51.8 \\
\hline & 20 & 0.545 & 12 & 1.01 & 10.15 & 1 & 38.6 & 39.5 \\
\hline \multirow[t]{5}{*}{$15 \times 15$} & 1.5 & 0.995 & 15.225 & 1.022 & 15.225 & 1.022 & 99.5 & 99.8 \\
\hline & 5 & 0.938 & 15.75 & 1.022 & 15.225 & 1.022 & 87.6 & 88.1 \\
\hline & 10 & 0.816 & 16.5 & 1.022 & 15.225 & 1.022 & 69.4 & 70 \\
\hline & 15 & 0.692 & 17.25 & 1.022 & 15.225 & 1.022 & 53.9 & 54.4 \\
\hline & 20 & 0.581 & 18 & 1.035 & 15.225 & 1.022 & 41.0 & 42 \\
\hline \multirow[t]{5}{*}{$20 \times 20$} & 1.5 & 0.998 & 20.3 & 1.035 & 20.3 & 1.035 & 99.8 & 99.9 \\
\hline & 5 & 0.944 & 21 & 1.035 & 20.3 & 1.035 & 88.2 & 88.4 \\
\hline & 10 & 0.83 & 22 & 1.035 & 20.3 & 1.035 & 70.6 & 70.9 \\
\hline & 15 & 0.713 & 23 & 1.035 & 20.3 & 1.035 & 55.5 & 55.8 \\
\hline & 20 & 0.611 & 24 & 1.041 & 20.3 & 1.035 & 43.4 & 43.9 \\
\hline \multirow[t]{5}{*}{$25 \times 25$} & 1.5 & 0.996 & 25.375 & 1.041 & 25.375 & 1.041 & 99.6 & 99.7 \\
\hline & 5 & 0.947 & 26.25 & 1.041 & 25.375 & 1.041 & 88.4 & 88.7 \\
\hline & 10 & 0.84 & 27.5 & 1.041 & 25.375 & 1.041 & 71.5 & 71.7 \\
\hline & 15 & 0.731 & 28.75 & 1.043 & 25.375 & 1.041 & 56.8 & 57.1 \\
\hline & 20 & 0.629 & 30 & 1.043 & 25.375 & 1.041 & 44.9 & 45.1 \\
\hline
\end{tabular}

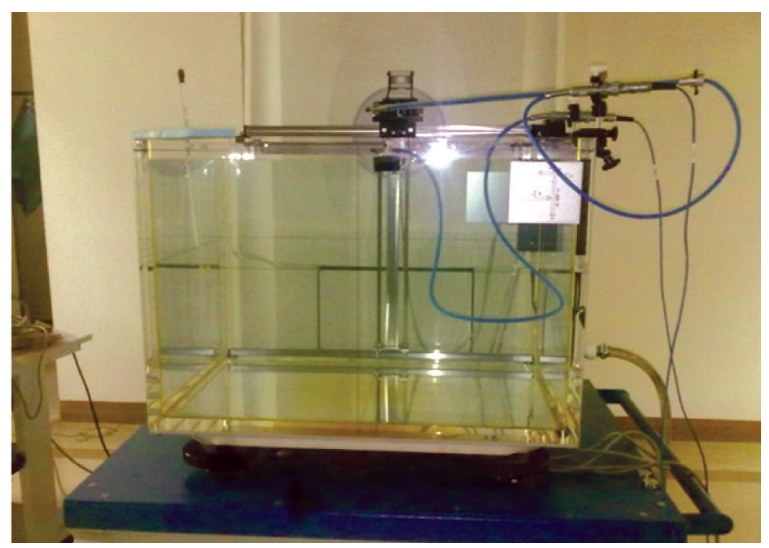

Fig. 1. Set-up of water phantom and ionisation chamber.
Table 2. Calculated PD values between measured and calculated values for $6 \mathrm{MV}$ photon beam

\begin{tabular}{|c|c|c|c|c|c|}
\hline \multirow{2}{*}{$\begin{array}{l}\text { Depth in } \\
\text { water }(\mathrm{cm})\end{array}$} & \multicolumn{5}{|c|}{ Field size $(\mathrm{cm} \times \mathrm{cm})$} \\
\hline & $5 \times 5$ & $10 \times 10$ & $15 \times 15$ & $20 \times 20$ & $25 \times 25$ \\
\hline 1.5 & 0.40 & 0.40 & 0.30 & 0.10 & 0.10 \\
\hline 5 & 0.11 & 0.57 & 0.56 & 0.22 & 0.27 \\
\hline 10 & 0.77 & 0.73 & 0.85 & 0.42 & 0.27 \\
\hline 15 & 1.04 & 1.5 & 0.91 & 0.53 & 0.52 \\
\hline 20 & 1.66 & 2.2 & 2.38 & 1.13 & 0.44 \\
\hline
\end{tabular}

Table 3 summarizes the conspicuous statistical values for PD and PD gradient.

Error range between maximum and minimum PD was 2.28 and between PD gradient was 0.1326 by origion Pro-7 software. 


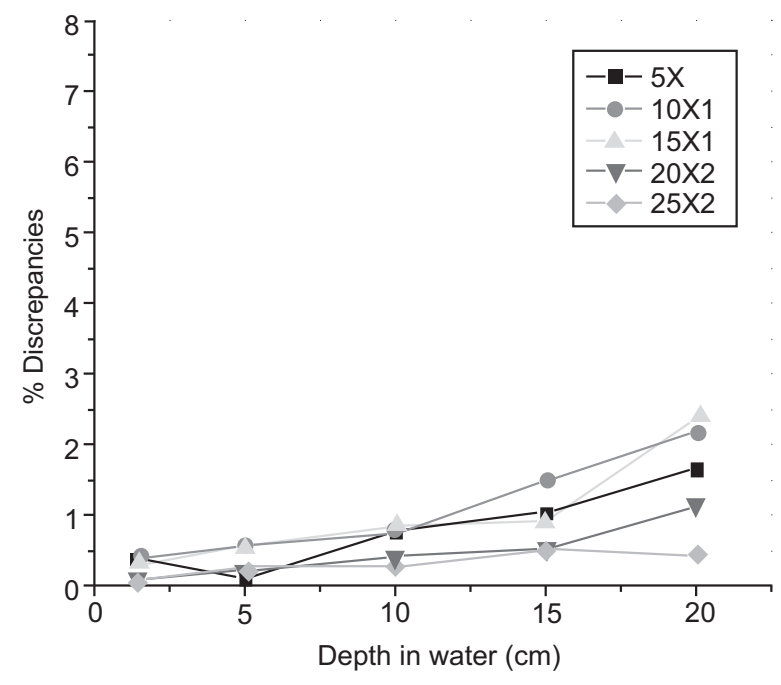

Fig. 2. Variation of $\mathrm{PD}$ with depth in water at $6 \mathrm{MV}$.

Table 3. Statistical summary of PD and PD gradient values

\begin{tabular}{lll}
\hline \hline & PD & PD gradient $\left(\mathrm{cm}^{-1}\right)$ \\
\hline Maximum & 2.38 & 0.1386 \\
Minimum & 0.10 & 0.006 \\
Mean & 1.24 & 0.0723 \\
\hline \hline
\end{tabular}

Previously, Sameer (2007) reported for comparative study of measurements. The PDD measurements were done between two different medical linear accelerators and the PD values were calculated. It was concluded that these discrepancies should be considered, while, delivering dose to the cancer patient.

\section{Conclusion}

Percentage discrepancies (PD) were found out between measured and calculated values. PD describes how much calculated values resemble to measured values. For the same depth and field sizes, PDDs were found minute different for both the measured and calculated values at $6 \mathrm{MV}$. PD ranged between a maximum of 2.38 and minimum of 0.010 with mean value of 1.24 for $6 \mathrm{MV}$. It may depend on some factors such as properties of measuring devices and movement of water during measurements. PD gradients were also calculated and found ranging between a maximum of $0.1386 \mathrm{~cm}^{-1}$ and a minimum of $0.006 \mathrm{~cm}^{-1}$ with a mean value of $0.0723 \mathrm{~cm}^{-1}$ for $6 \mathrm{MV}$.

\section{Acknowledgement}

Authors are thankful to Higher Education Commission of Pakistan and Radiation Oncology Department, Shaukat Khanum Cancer Hospital and Research Centre, Lahore, providing facilitations to complete this project.

\section{References}

Ahnesjo, A., Aspradakis, M.M. 1999. Dose calculations for external photon beams in radiotherapy. Physics in Medicine and Biology, 44: R99-R155.

Birgani, M.J.T., Karbalaee, S.M. 2009. Calculation of anylitical expressions for measured percentage depth dose data in megavoltage photon therapy. Iranian Red Crescent Medical Journal, 11: 140-144.

Bloch, P., Altschuler, M.D. 1995. Three-dimensional photon beam calculations. In: Radiation Therapy Physics, Medical Radiology, A. R. Smith (ed.), pp. 33-42, Springer Berlin Heidelberg, Germany.

IAEA, 2000. Absorbed Dose Determination in External Beam Radiotherapy: An International Code of Practice for Dosimetry Based on Standard of Absorbed Dose to Water, Technical Report Series No. 398, International Atomic Energy Agency (IAEA), Vienna, Austria.

Khan, F.M. 2010. The Physics of Radiation Therapy: M-Medicine Series, 531 pp., $4^{\text {th }}$ edition, Lippincott Williams \& Wilkins Ltd., Baltimore, USA.

Peter, R.A., Peter, J.B., Coursey, B.M., Hanson, W.F., Huq, M.S., Nath, R., Rogers, D.W.O. 1999. AAPM's TG-51 protocol for clinical reference dosimetery of high-energy photon and electron beams. Medical Physics, 26: 1847-1870.

Rogers, D.W. 2002. Monte Carlo techniques in radiotherapy. Medical Physics, 58: 63-70.

Sameer, S.A.N. 2007. A comparative study of measured percentage depth doses for two medical linear accelerators. Umm Al-Qura University Journal of Science Medicine and Engineering, 19: 145-151. 